Osborne Clarke is one of Europe's most respected law firms and a UK leader in advising marketers on the legal issues affecting them. The firm's website, MarketingLaw.co.uk, has provided marketers with authoritative legal insights for over 10 years. Please send any queries regarding this column to Stephen Groom (Stephen. groom@ osborneclarke.com)

What happened

'By early 2015' bombshell drops

\section{Legal and Regulatory Update}

\section{One step forward, two steps back for EU data reforms}

\section{Stephen Groom}

Journal of Direct, Data and Digital Marketing Practice (2014) 15, 233-235. doi:10.1057/dddmp.2013.70

Who: Civil Liberties, Justice \& Home Affairs Committee of the European Parliament (LIBE) and the European Council

Where: Brussels

When: October 2013

In the space of just 5 days in October 2013, EU data privacy law reforms took one step forward, then two steps back. First, after weeks of negotiations in windowless rooms, it seemed that with one bound the much-delayed process of agreeing reforms to Europe's data protection laws was back on track.

On 21 October 2013, the powerful LIBE committee published a revised draft 'compromise package' Regulation. Some criticized it as in some respects unworkable, but the general consensus seemed to be that a reasonably workman-like job had been done to blunt some of the sharper edges of the earlier draft. From here, it was felt that Euro MPs, the European Council and the European Commission should be able to push on in their 'trialogue' discussions, knock heads together and complete the final negotiation rounds before all bets were off in Spring 2014, when Euro MPs and Commissioners stood down for fresh elections.

Marketers scrutinized the new draft and took some crumbs of comfort. Although many of the eye-watering changes were still in place, others that had caused sleepless nights had lost some of their sting. At least one leading data protection expert expressed confidence that all would be resolved on schedule in early 2014.

But then, as pundits, industry bodies and advisers got to grips with the detail of yet another draft - as ever not knowing whether any of these might end up on the statute book - the next bombshell dropped. At the end of the European Council meeting in Brussels on 25 October 2013, a communiqué was published with various conclusions. One mentioned the importance of ensuring that various proposed EU measures reached the statute book before the end of the current legislative period, in other words before spring 2014.

There was no mention here, however, of data protection reform. This was in the next conclusion, which read: 'The timely adoption of a strong EU General Data Protection Framework [is] essential for the completion of the Digital Single Market by early 2015'. 


\section{Some changes in the latest draft}

Therefore, there between the lines it was almost plain to see. The conclusion pointed strongly to there being no sign-off until 2015, and thus with a 2-year lead-time baked into the draft Regulation, it was going to be 2017 before any new data laws had to be obeyed.

In a press conference, PM David Cameron claimed credit for the indication of delay, saying: 'We do need to have a data protection directive in the EU, but the current draft would add a lot of cost to businesses. It's not right, so I made sure there was no false deadline for that one'.

So there things stand, at least at the time of writing, but there could yet be a twist in the tale. EU sources emphasize that the wording of the conclusion still allows for the possibility of introducing the new measure before 2015 .

In the meantime, just for the record, here are some of the headline provisions of the 21 October 2013 draft, which will be of more interest to marketers:

1. fines for breach up to a maximum of the greater of $€ 100 \mathrm{~m}$ or 5 per cent of global turnover (this was $€ 1 \mathrm{~m}$ or 2 per cent of turnover in the first draft back in 2011);

2. any company processing personal data on more than 5,000 individuals must appoint a Data Protection Officer (the threshold was previously 500 employees);

3. although the picture is not clear, it seems possible that profiling for marketing purposes may escape the full rigours of prior explicit consent. The latter is only needed if the profiling leads to 'legal effects' or 'significantly affects the data subject'.

4. the new 'European Data Protection Board' - which in reality will be the Article 29 Working Party by another name — will be tasked with producing guidelines on a wide range of areas, such as:

$\circ$ profiling that significantly affects the interests, rights or freedoms of the data subject; and

- methods of verifying consent when processing children's personal data.

5. a helpful new draft format in which the recitals relevant to a particular Article appear below that Article rather than in the Recitals section at the beginning. It would be good if this remained the format in the final measure, but sadly this is unlikely;

6. an interesting new approach to present privacy policy information in an intelligible and accessible way using standard symbols, such as:

- a circle with three figures in it symbolizing 'No personal data are disseminated to commercial third parties';

- a bag of Euros held by a disembodied hand symbolizing 'No personal data are to be sold or rented out'.

While the revised draft Regulation takes significant strides towards the final measure, there can be no doubt that interest in its detailed provisions has waned since the 'conclusion' of the European Council harbingered the likelihood of significant delay until 2015. And not without justification. 
With over a year of negotiations now still to go, there have to be significant prospects of many more twists and turns in the drafting process. This will undoubtedly mean more opportunities for lobbying by the marketing industry. Whether this will lead to significant rowing back from some of the harsher changes for marketers, however, remains to be seen.

Stephen Groom, co-chair - advertising and marketing law group, deputy chair - privacy and data law group, Osborne Clarke.

\section{New guidance on cookie consent laws}

\section{Sue Gold}

Journal of Direct, Data and Digital Marketing Practice (2014) 15, 235-238. doi:10.1057/dddmp.2013.71

Who: Article 29 Working Party

Where: European Union

When: October 2013

Law stated as at: November 2013

What happened

\section{Background}

The Article 29 Working Party issued a Working Document (Opinion) providing guidance on how to obtain consent for the use of cookies and similar tracking technologies (cookies). The Working Party guidance is non-binding but represents the view of the Data protection authorities across the EU.

The e-Privacy Directive 2002 was amended in 2009. One key provision impacting marketers was Article 5.3, requiring consent to be obtained for the storage of cookies and similar technologies. This replaced the previous practice of merely notifying users that cookies were used (usually in privacy policies) and explaining to users how to opt out from the use of cookies.

The Information Commissioner's Office (ICO) was one of the first regulators to provide guidance and allowed for a period for implementation until May 2012. The ICO's Guidance accepts that some form of implied consent may be acceptable for the use of non-intrusive cookies, for example, those used for analytics of aggregated data. A number of other countries have slowly been implementing the amendment and, after various interpretations, many have now followed the United Kingdom in allowing for implied consent.

A range of practical implementations has been developed by websites in order to obtain consent for the use of cookies used for various purposes (from enhanced functionalities to analytics, targeted advertising and product optimisation and so on, by website operators or third parties). 